\title{
Electroforming of a Complex Mould Using an Acid-Mediated Copper Sulphate Bath
}

\author{
R. T. 0jo1, C. Edechuku1, B. Aremo2*, M. O. Adeoye1, 0. S. Teniola1 \\ ${ }^{1}$ Department of Materials Science and Engineering, Obafemi Awolowo University, Ile-Ife, Nigeria \\ ${ }^{2}$ Centre for Energy Research and Development, Obafemi Awolowo University, Ile-Ife, Nigeria \\ Email: roslynojo@yahoo.co.uk, Chukudi.Edechuku@gmail.com, ㅎolaji_aremo@yahoo.com, \\ madeoye@oauife.edu.ng, oluwasanminteni@yahoo.com
}

Received 31 January 2014; revised 3 March 2014; accepted 10 March 2014

Copyright (C) 2014 by authors and Scientific Research Publishing Inc.

This work is licensed under the Creative Commons Attribution International License (CC BY).

http://creativecommons.org/licenses/by/4.0/

(c) (i) Open Access

\begin{abstract}
This work reports a procedure for the fabrication of a complex mould using the technique of electroforming. This was with a view to finding a cheaper and less labour-intensive mould production route practicable locally. A Plaster of Paris electroforming mandrel in the shape of a water bottle was produced and made electrically conducting with a layer of copper conducting paint. Considerations for electroform removal were made by applying a thin, chloroform-dissolvable epoxy layer beneath the conducting copper paint. Uniformity of deposition on the mandrel was accomplished with the construction of a special deposition bath with multiple copper anodes around its perimeter. The electroforming was done in the galvanostatic electro deposition mode for about 240 hrs in a $1 \mathrm{M} \mathrm{Cu}_{2} \mathrm{SO}_{4}$ bath with the deposition of elemental copper on the mandrel. Incidences of rising bath $\mathrm{pH}$ were mediated with concentrated $\mathrm{H}_{2} \mathrm{SO}_{4}$. A free-standing electroform representing the mould cavity was formed in the deposition. The product so formed was a reproduction of the net-shape of the mandrel exhibiting smooth surface finish. The electroforming was cast with an aluminum backing layer to complete its transformation into a split mould. The finished mould was comparable in appearance to the imported moulds in terms of appearance and reproduction of intricate surface patterns. The simplicity and low cost of this method significantly reduced the requirements for expensive instrumentation and highly skilled labour for mould production.
\end{abstract}

\section{Keywords}

Electroforming, Electroform, Mould, Copper, Electrodeposition

\section{Introduction}

The technological coming of age of a society is often measured by its ability to produce components and physi-

${ }^{*}$ Corresponding author. 
cal products needed by its citizenry. Industrial and consumer products, tailor-made in local industries to suit the cultural and environmental needs of the people are often a sign of economic maturity of a society. In this context, mould making know-how is of utmost importance because it turns design concepts and prototypes into end products available to the consumer. Globally, current mould making techniques are faced with challenges stemming from rapid rates of product innovation and demands for reduced lead time. This problem has been further exacerbated by requirements of the moulds industry to tackle the additional complexity of the one-of-a-kind production type [1].

A mould is a system for reproducing multiple copies of a design such that any two random samples are indistinguishable from each other. Many industries cannot function without moulds. Industries such as automobile manufacturing, consumer electronics and medical prosthetics all rely on moulds and access to customised mould making know-how. As such, the lack of mould making capabilities in Nigeria has prevented many of these industries from taking off locally, in the process of depriving the country of much needed technological development and employment creation opportunities.

Mould making is poorly developed in the country because it is a very expensive and complicated process requiring sophisticated instrumentation and highly skilled operators. It usually takes 3 - 5 years for operators to be properly trained [2]. This is traceable to the conventional methods of mould making such as the use of Computerised Numerical Control machining centres and Electro discharge machining. Hence, local industries relying on moulds such as plastic, ceramic and building materials industries import their moulds at high costs. Mould making industry is an elite global club. International trade in industrial moulds is concentrated in a few countries; about 25 countries represent close to $90 \%$ both of imports and exports [3].

One approach to overcoming the mould-maker's difficulties would be to make the mold-making process less dependent on human skills [4]. Mould making could be significantly simplified if the need for skilled human involvements and expensive process machinery is reduced.

Electroforming is a derivative of electroplating. Both processes rely on the reduction of elemental metals from aqueous bath of positively charged cations, through the application of negative potentials on a cathode. Electroplating products are widely used by many industries, such as automobile, ship, aero-space, machinery, electronics, jewelry, defense, and toy industries [5]. Electroforming is however different. Electroforming has been described as "the production or reproduction of articles by electro deposition upon a mandrel or mould that is subsequently separated from the deposit" [6]. This definition underscores the fact that whilst electroplating typically produces deposits a few microns thick which are retained on the part, and electroforming deposits are much thicker and are later removed as free-standing objects. Inherent in this process is its ability to accurately capture intricate surface details on a mandrel. This attributed has encouraged the use of the technique in diverse fields. Electroforming has been applied in diverse fields from the production of fuel cell bipolar electrodes components [7], and in decorative fixtures and in art works. The technique is however faced with some key constraints. Chief amongst these is the challenge of finding suitable mandrel material that would facilitate ease of electroforming removal.

This work reports a mould forming method which makes use of the inherent ability of electroforming to accurately capture surface details. Selection and preparation of mandrel material and the construction of a deposition bath for uniform deposition are presented. Also, a casting procedure to incorporate a backing layer on the electro form was developed to complete its transformation into a split-mould.

\section{Experimental Procedure}

A constant current electro deposition procedure (galvanostatic) was utilized in this work due to its inherent ability to achieve faster deposition times. In this work, though the DC source was rated at $19 \mathrm{~V}(3 \mathrm{~A})$, the measured actual deposition potential fluctuated in the region of $0.8 \mathrm{~V}$ and $1.2 \mathrm{~V}$.

\subsection{Electroform Pattern}

A plastic bottle blowing half-mould which was developed in this work was based on the bottle design of Obafemi Awolowo University Bottled Water (Obafemi Awolowo University Investment Company Limited, Ile-Ife). A Plaster of Paris (POP) mandrel was moulded by casting wet POP into a split section of the plastic bottle. The split section of the bottle and the POP mandrel are shown in Figure 1. 


\subsection{Mandrel Fabrication}

Electroforming mandrels are usually made of friable materials to facilitate later ease of removal using mechanical or chemical means. In this work POP was used as the material for the mandrel due to its low-cost and ease of moulding. The POP mandrel is schematically illustrated Figure 2. From the figure, the mandrel could be seen to be layered. Just on top of the POP is a layer of epoxy. This layer was necessary to facilitate the removal of the electroform. The epoxy, being a plastic could be dissolved off using an organic solvent such as chloroform. The gap created by the epoxy's dissolution further aids the electro form's removal. After the epoxy layer is the

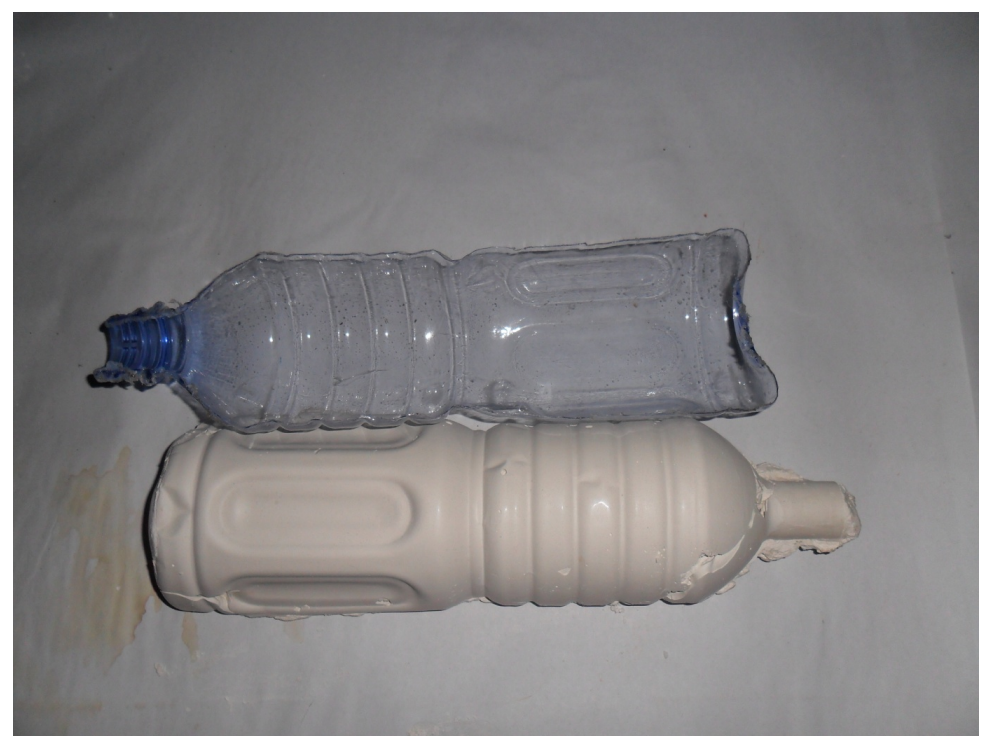

Figure 1. Longitudinally split section of the plastic bottle and the cast POP mandrel.

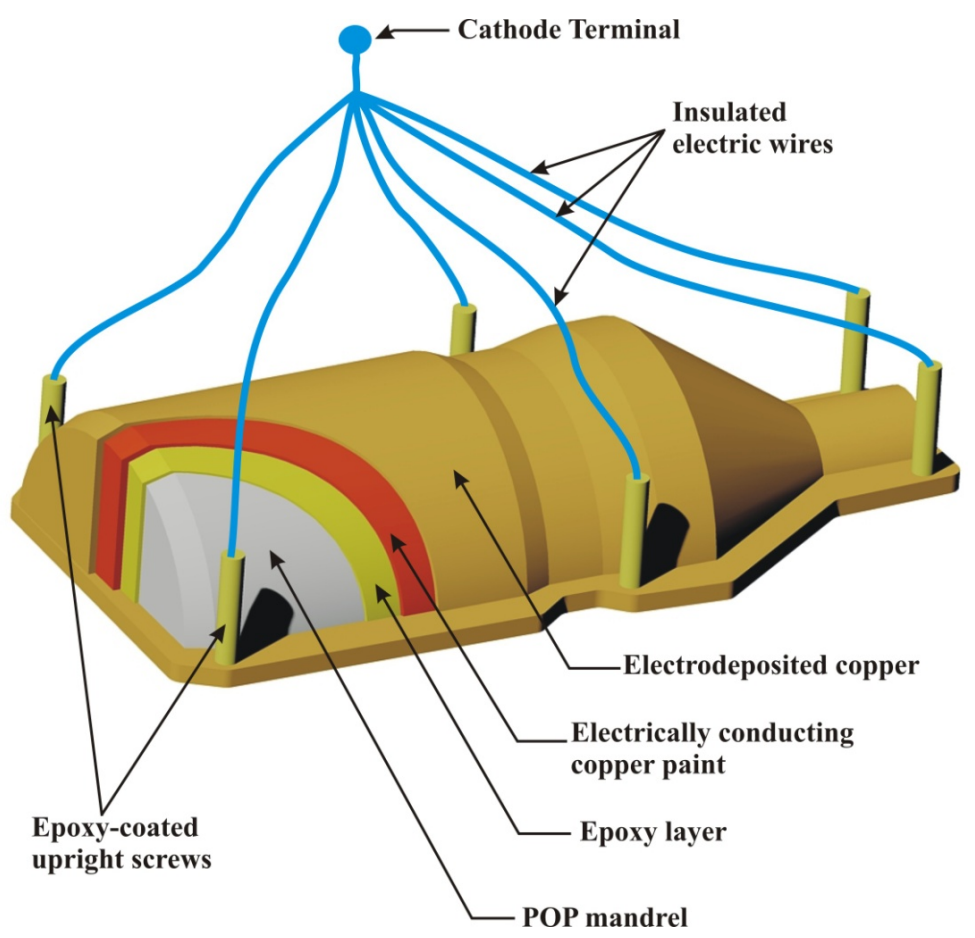

Figure 2. Cut-through view of the electroform mandrel showing the different layers. 
layer of conducting paint. The deposition of copper occurs on top of this layer. After allowing for proper curing of the POP for about 3 days, the slow-curing epoxy was poured and applied on top using a brush. The thin epoxy layer was allowed to cure for about 2 days, and then the copper conducting paint was brushed on top. This copper conducting paint was allowed to dry for about 4 hours in the sun, and then it was fully cured by baking in an electric oven at $80^{\circ} \mathrm{C}$ for 2 hrs. The mandrel with copper paint layer is shown in Figure 3.

\subsection{Deposition Bath}

The design of the deposition bath is illustrated in Figure 4. The deposition bath was prepared using the bottom

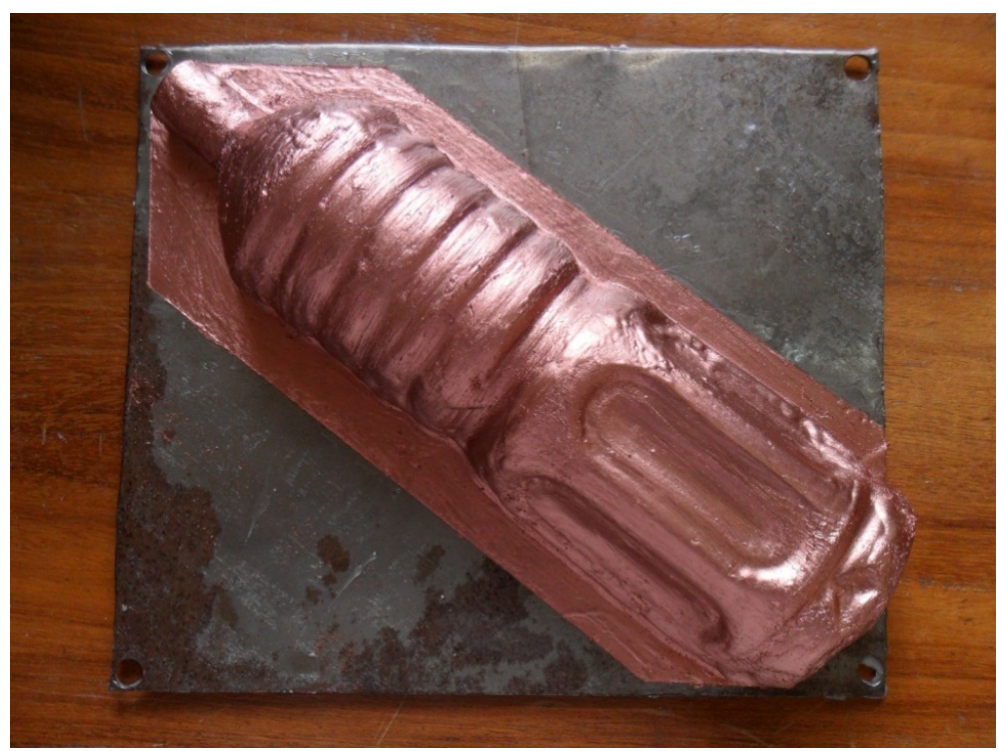

Figure 3. POP mandrel with the copper conducting paint layer applied.

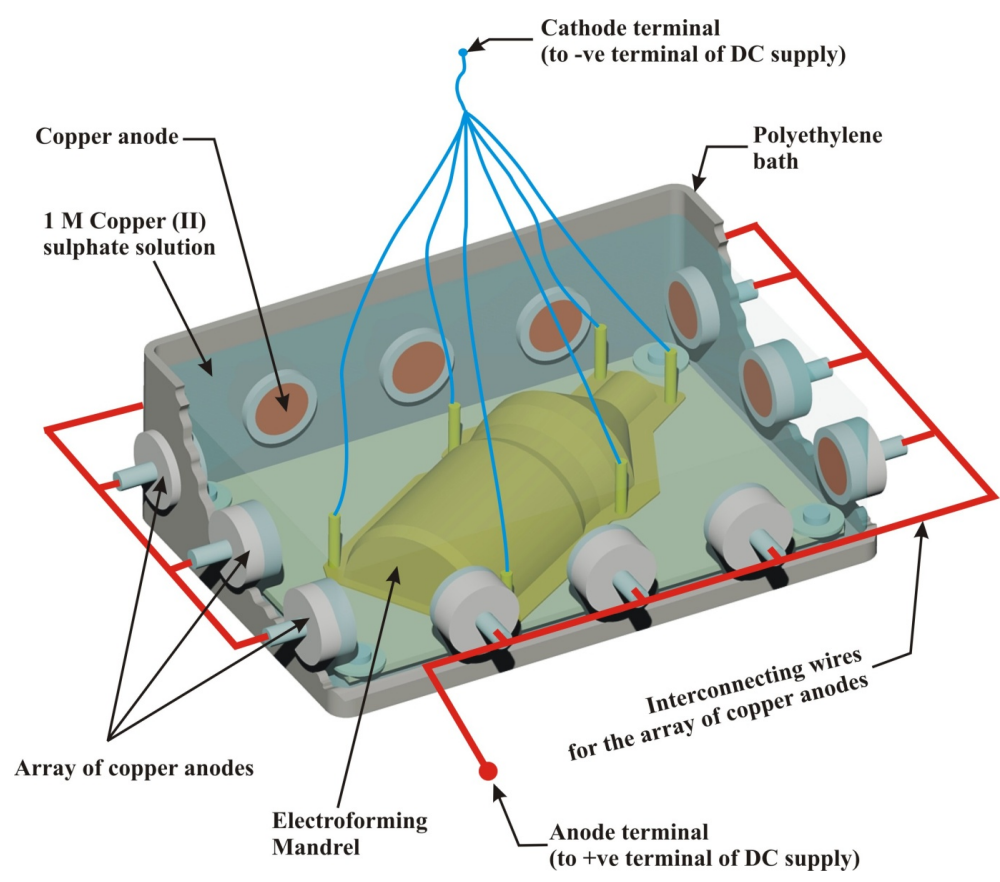

Figure 4. The cut-through view of the electro deposition bath showing the positioning of the mandrel in the bath and the arrangement of copper anodes around its perimeter. 
half of a 25 litre plastic keg. The problem of incomplete or non-uniform deposition on the cathode is common in electro deposition. In this work, the problem was mitigated through the use of multiple anodes, arranged uniformly around the perimeter of the mandrel as shown in the Figure 4. A square, steel base-plate with diagonal length longer than the mandrel was fabricated. The base plate was coated with epoxy to render it non-electrically conducting. Four $8 \mathrm{~mm}$ diameter holes were drilled at the corners of the plate to be bolted to the bath's bottom. The mandrel was mounted on the base-plate with epoxy.

A copper sulphate deposition bath was used in this work. This enabled the deposition of elemental copper as the electroformed material. A $1 \mathrm{M}$ copper sulphate (BDH Chemicals, Poole England) was thus prepared; the pH was maintained to about 2.5 and 3.0 using concentrated $\mathrm{H}_{2} \mathrm{SO}_{4}$.

\subsection{Preparation Copper Anodes}

The copper anodes were fabricated from bundles of 32 SWG electrical-grade copper wire. The wires were cut into short lengths and assembled in bundles of about 50 pieces. One end of the bundles was soldered together (to electrically establish contact between the individual pieces) and then attached to the head of an M8 stainless steel screw. The assembly was placed inside the specially constructed Teflon cups and invested with epoxy (araldite). After the epoxy cured, the free end of the wire bundle was polished to expose the end sections of the bundle.

\subsection{Deposition Procedure}

The base-plate with the mandrel on top was bolted to the bottom of the bath and the $1 \mathrm{M}$ copper sulphate solution was poured inside to completely cover the mandrel and reach above the level of the copper anodes (see Figure 4). The flexible wires attached to the upright screws were connected together at their free ends, to form a cathode terminal. The array of copper anodes was connected together in series with flexible wire to form a single anode electrode (see Figure 4). The DC power supply unit was connected with the positive terminal to the anode and the negative terminal to the mandrel. Deposition was done for about 240 hours.

\subsection{Post-Electroforming Operations}

After the electroforming of the free-standing copper, the following post-electroforming operations were carried out for mandrel removal and incorporation of aluminium backing layer.

\subsubsection{Mandrel Removal}

After the deposition process, the electroforming was removed by dissolving the epoxy layer just beneath the electroforming (see Figure 1) with chloroform. The gap thus created by the epoxy layer's removal loosened up the electroform from the POP mandrel. Some sections of the underlying POP were gouged out, after which the electroform came off freely.

\subsubsection{Incorporation of Aluminium Backing Layer}

In this work, an aluminium backing layer was incorporated on the electroform. The process steps for incorporating the backing layer is illustrated in Figure 5. The electroform was positioned inside a ceramic mould as shown in Figure 5(a). The aluminium charge for the backing layer was melted in an electric resistance furnace. About 30 min prior to pouring in the melt into the mould cavity, the electroform and the mould cavity were preheated using a 500 watt flood lamp, to about $120^{\circ} \mathrm{C}$ (see Figure $5(\mathrm{~b})$ ). The melt was superheated by $40^{\circ} \mathrm{C}$ above aluminium's melting point $\left(660^{\circ} \mathrm{C}\right)$ to about $700^{\circ} \mathrm{C}$, and it was poured directly on top of the electroform inside the mould, completely covering it up (see Figure 5(c)). The cast-assembly was allowed to cool naturally to room temperature. The mould was broken up and the cast half of the mould, with the electroform now embedded inside, was removed.

\section{Results and Discussion}

Figure 6 shows the electroformed mould after about 240 hours of deposition. The brightly shining reddishbrown luster is however tarnished after a while of being exposed to air. The interior view of the electroform is shown in Figure 7. The actual thickness at any point on the surface depends on the current density at that point. 

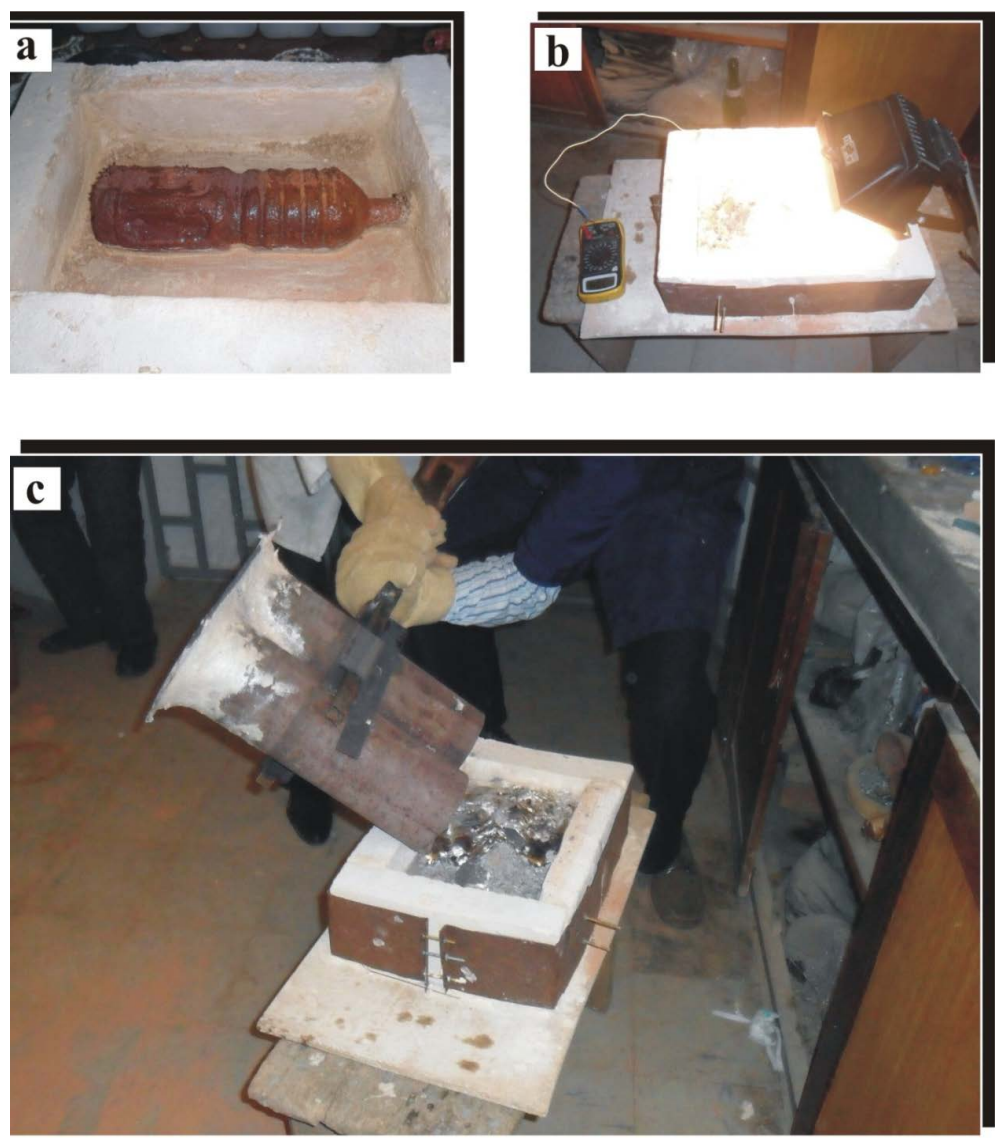

Figure 5. (a) The electroform was positioned inside an open mould; (b) The mould was preheated for about 30 min to $120^{\circ} \mathrm{C}$ with floodlights; (c) The molten aluminium was poured directly on top of the electroform.

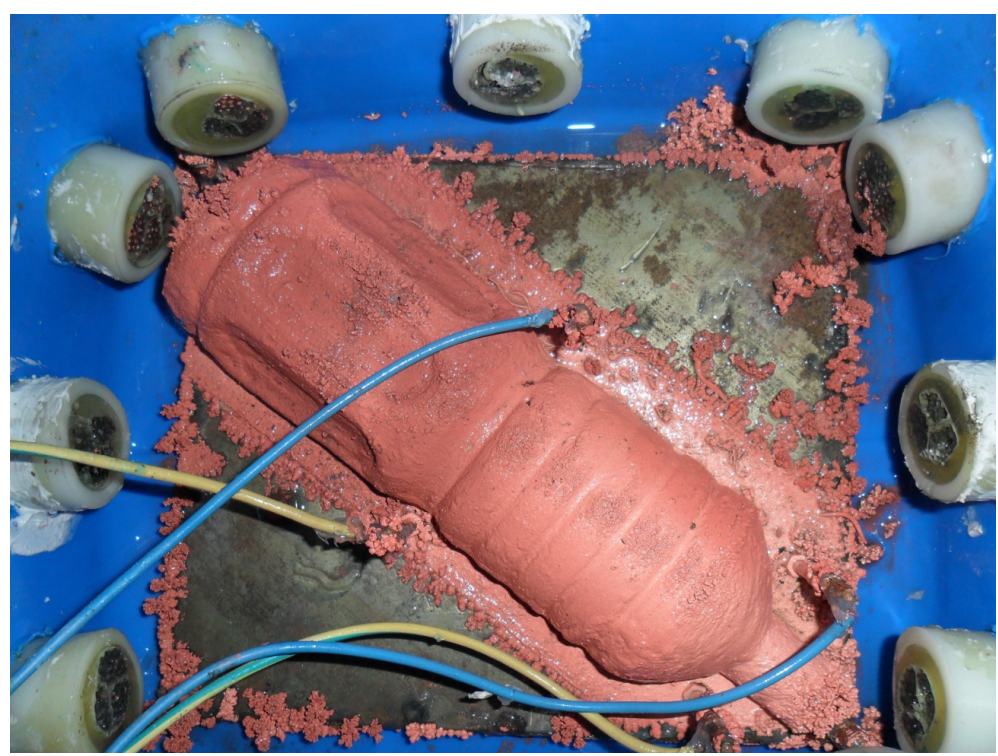

Figure 6. The electroformed copper shell after about 240 hrs deposition.

The current density at any point is determined by how the current is apportioned over the surface of the article being electroplated [8]. 
The outer shell of the electroform as seen in Figure 6 appeared rough, however, the interior cavity of the electroform (Figure 7) was very smooth to the touch, and accurately recreated the intricate patterns on the mandrel's surface.

\subsection{Appearance of the Mould}

The finished half-mould after the incorporation of the backing layer is presented in Figure 8. Depending on the level of complexity required of the mould, the mould cavity could be further designed to have channels or pathways for the flow of mould coolants, or have locking pins for attachment to the other half-mould. Also, fixtures for attachments to moulding equipment could be provided for in the mould prior to incorporating the backing layer.

\subsection{Problems Encountered in the Bath}

A series of problems were experienced in the course of the deposition. These problems and solution methods developed and proposed for their mitigation are presented below.

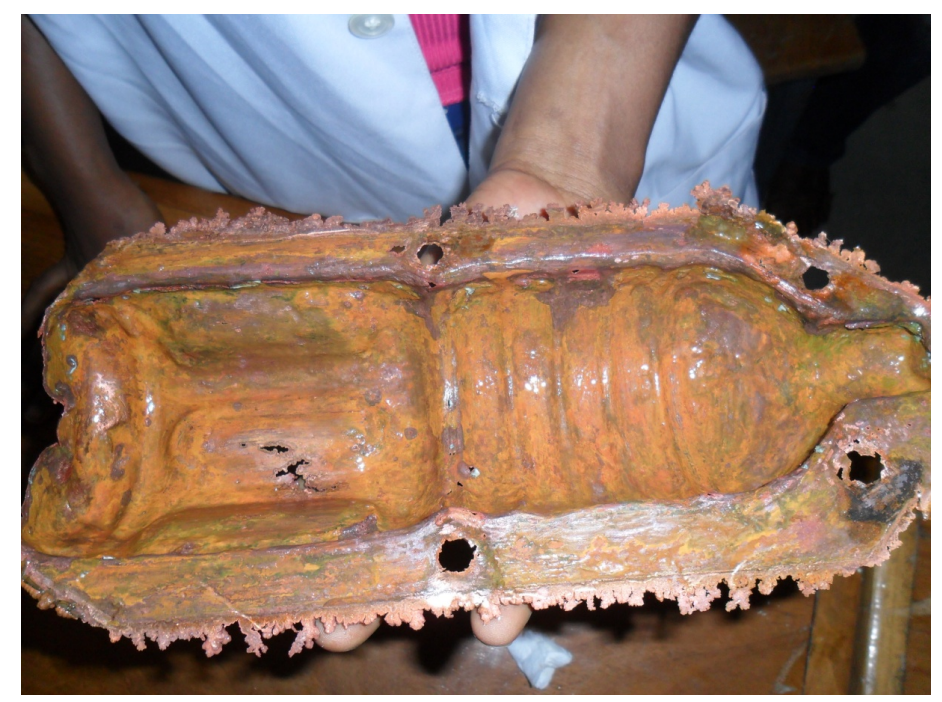

Figure 7. The interior view of the electroformed copper insert.

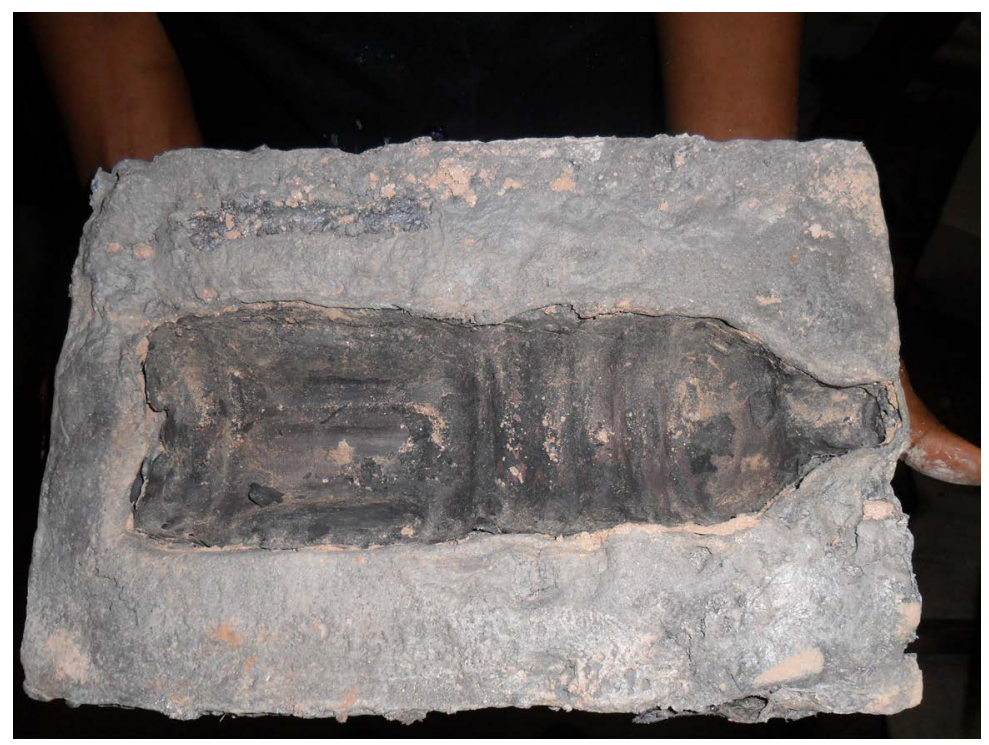

Figure 8. The finished half-mould after the incorporation of the backing layer. 
i. $\quad$ Rising $\mathbf{~ p H}$ level: The rise in the deposition solution's $\mathrm{pH}$ was noticed; if unchecked this could lead to $\mathrm{pH}$ "runaway" with unfavorable consequences. If the $\mathrm{pH}$ of the bath is allowed to stray above 9.0, $\mathrm{Cu}_{2} \mathrm{OH}$ would be deposited on the mandrel instead of elemental copper. The straying of the $\mathrm{pH}$ to the region of 9.0 was observed to occur at about 24 hrs intervals. Hence, in order to return the $\mathrm{pH}$ to within the window suitable for copper's deposition, it was necessary to add drops of concentrated $\mathrm{H}_{2} \mathrm{SO}_{4}$.

ii. Incomplete deposition coverage: Another problem encountered was the incomplete coverage of the top ridge of the mandrel in the deposition. This was attributed to the absence of copper anodes at the top of the bath in the original bath design (see Figure 9).

This problem is shown in Figure 9 after about 48 hours of deposition. This problem was mitigated by stretching a twisted length of 32 SWG copper wires diagonally across the bath as shown in Figure 10. The twisted copper wire was incorporated with the rest of the copper anodes. In this way, deposition at the top ridge of the mandrel was achieved. However, due to the depletion of the copper wire length with time, it had to be replaced

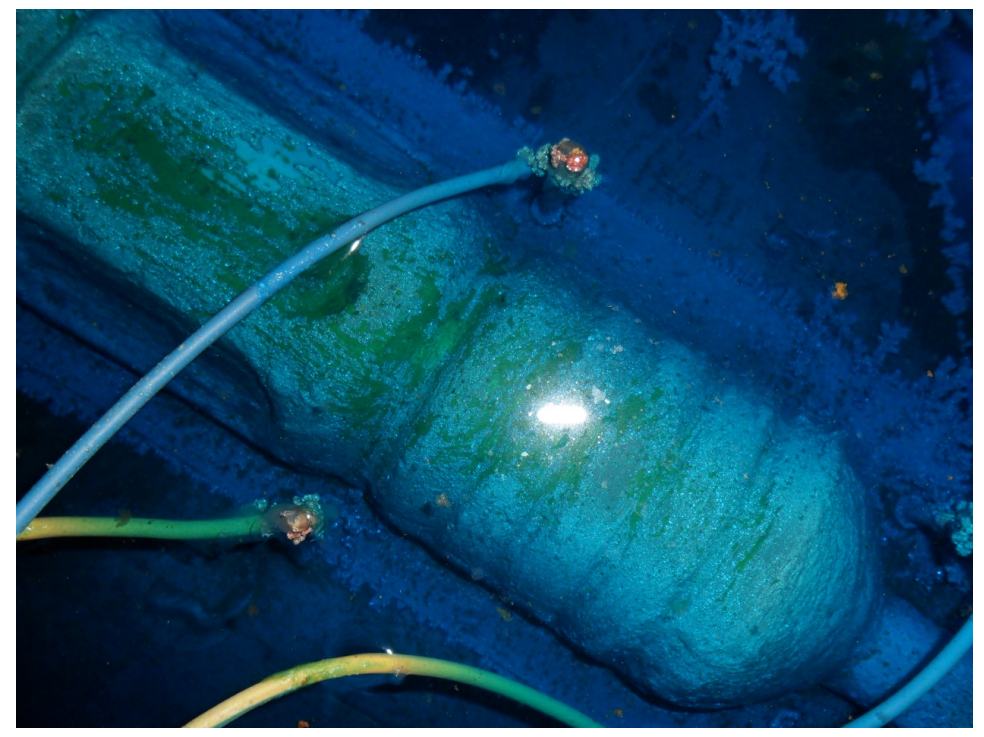

Figure 9. Problem of incomplete coverage of deposition on the top ridge of the mandrel.

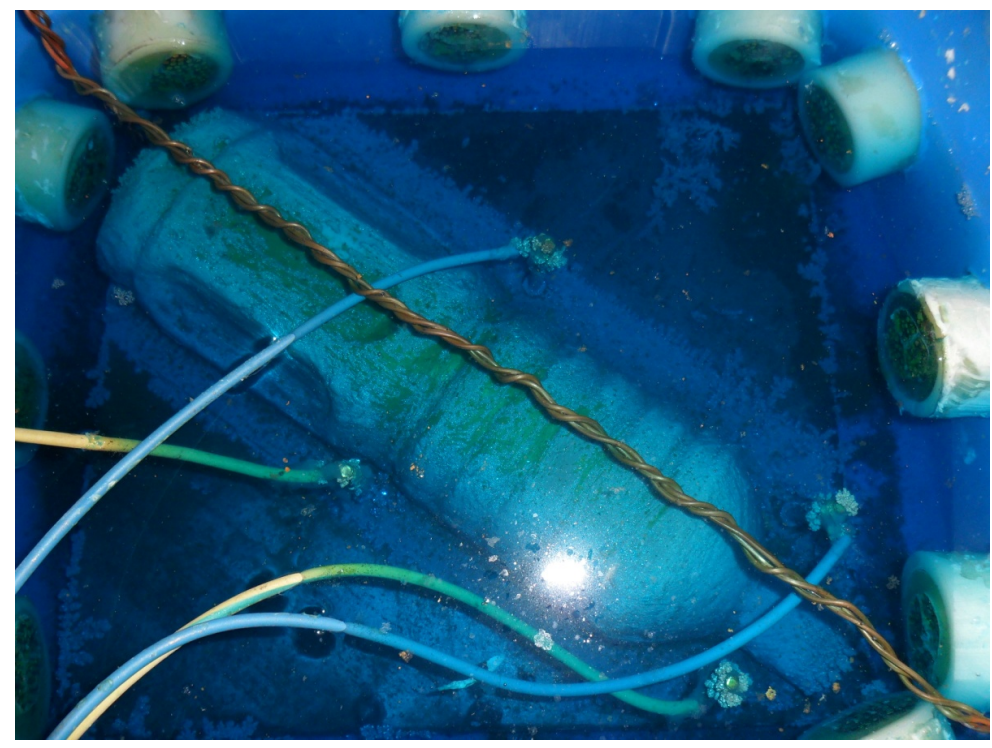

Figure 10. Twisted 32 SWG copper wires stretched diagonally inside the bath to encourage deposition on the top ridge of the mandrel. 
with a fresh one roughly every 24 hours.

iii. Growth of copper noodles: Noodle-like copper structures grow upright and flower-out at sharp points on the mandrel and on the upright screws that formed the cathode terminal. These structures are shown in Figure 11. Arrows A show an advanced growth of this noodle-like structure, about to touch the diagonal copper anode, while arrow B shows smaller-sized copper noodles. The noodle-like structures form at regions of localized high current density (sharp points), and grow outward in a direction towards the anode. In time, they touch the anode (see Figure 12). This is an unfavourable situation because it short-circuits the power supply and could damage it. The noodles thus have to be periodically broken up as they approached anode terminals to forestall damages to the power supply unit.

iv. Growth of copper through cracks and fissures on the base plate: A major problem was growth of copper through cracks and fissures in the epoxy insulating layer on the steel base plate. This is shown in Figure 13.

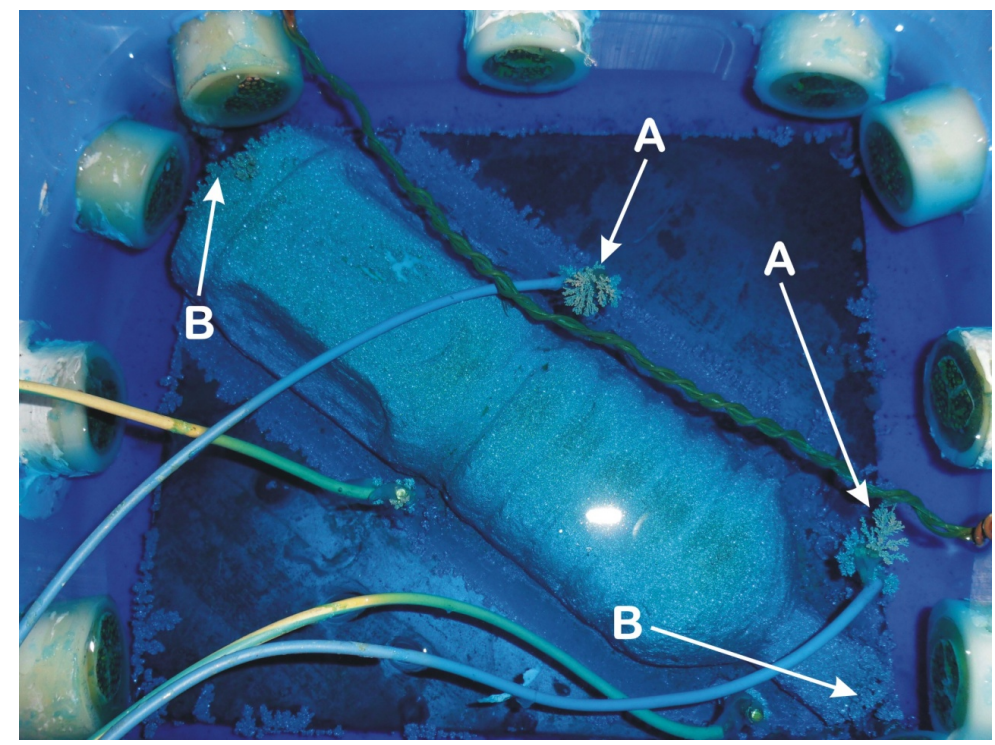

Figure 11. Copper noodles-like structures growth in the deposition bath. Arrows A show well developed dendrites while arrows B show smaller dendrites at sharp ends of the mandrel.

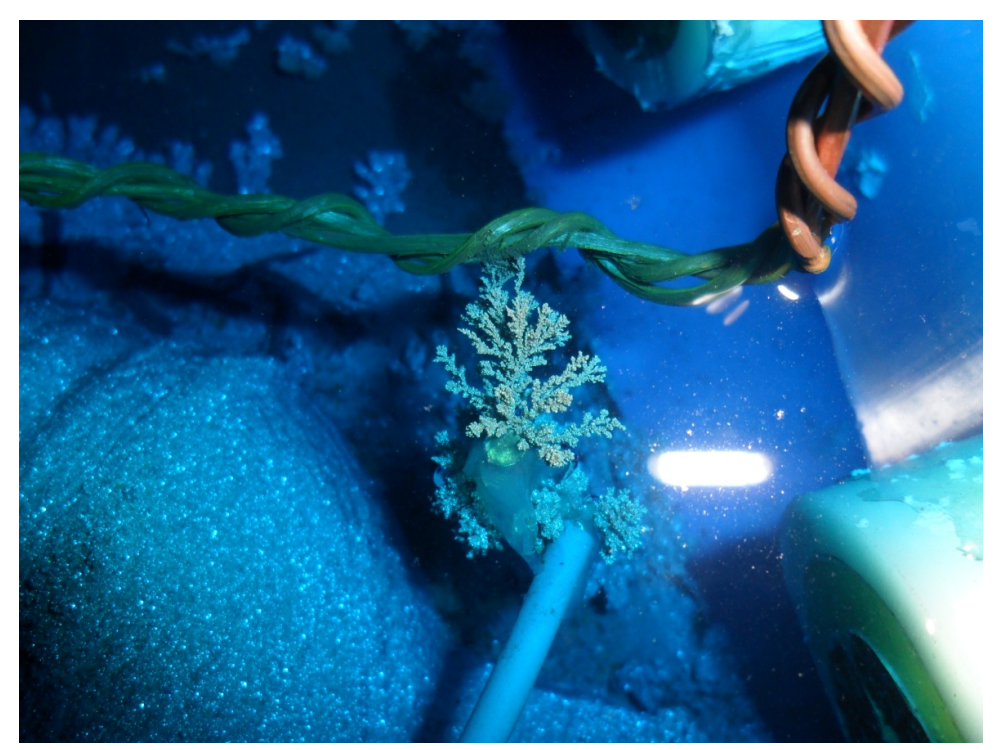

Figure 12. One of the noodles branching out, eventually touching the diagonal copper anode. 


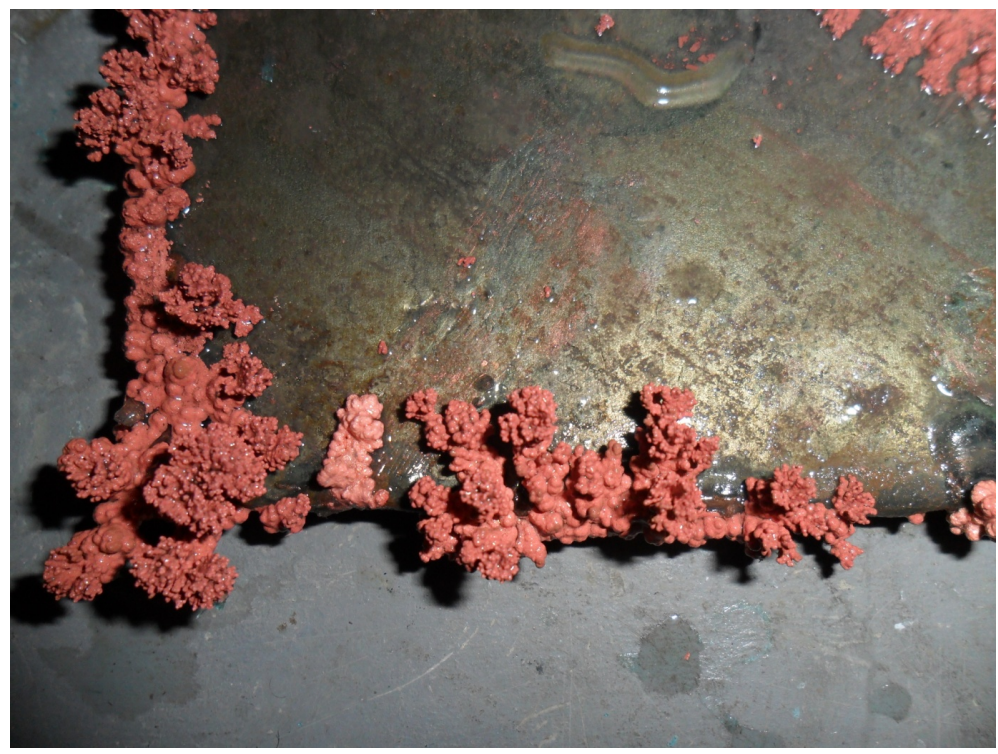

Figure 13. Parasitic growth of copper through cracks and fissures in the epoxy-coated steel base plate.

This kind of growth is considered parasitic and wasteful since the deposited materials do not form part of the electroform. An extra-thick layer of epoxy might resolve this problem, or better still; a wholly plastic base plate might be used.

v. Bath evaporation: Evaporation of the electrolyte was also noticed to occur as deposition progressed. This was attributed to the tendency for the bath temperature to rise to about $70^{\circ} \mathrm{C}$ as deposition progressed. Hence, every 24 hours, more $1 \mathrm{M} \mathrm{CuSO}_{4}$ was added to ensure that the mandrel and copper anodes remain completely covered.

\section{Conclusions}

This study has been able to demonstrate a simple technique based on electroforming and metal casting for the production of net-shape mould cavities. The study underscored the simplicity of the process, as measured by the ease of setting-up and low material costs.

Bath constitution and method of control of bath $\mathrm{pH}$ were discussed. This technique could be further improved upon by adding some degree of automation, especially for the control of bath $\mathrm{pH}$ and the replenishment of evaporated electrolyte. Deposition time in this process is influenced by the current rating of the DC source. Higher amperage DC power supply would significantly reduce deposition time from 240 hours needed for the electroformed water bottle mould. Oxidation of the electroformed copper can be prevented by dipping it in cold water immediately after removal from the bath.

The procedures developed in this work, can be applied to other metal beyond copper. With a little more refinement, would literally open the door for product development and inspire diverse local industries. This would provide a homegrown solution to the age long problem of mould importation in the country.

\section{References}

[1] Peças, P. andHenriques, E. (2003) The Need for Agile Manufacturing Implementation in Mould Making Business. In: Putnik, G.D. and Gunasekaran, A., Eds., Proceedings of the Business Excellence I-Performance Measures, Benchmarking and Best Practices in New Economy, Escola de Engenharia da Universidade do Minho, Braga, 321-326.

[2] Itoga, S. (1998) The Challenge to Enhancement of the Technological Level of Thailand. APEC Study Centre: Institute for Developing Economies, Tokyo.

[3] Beira, E. and Menezes, J. (2006) European Tooling and Mould Making Industry: Global Perspective and Italy Role. Working papers “Mercados e Negócios” TSI, Escola Engenharia Universidade do Minho, Braga.

[4] Choi, B.K., Ko, K. and Kim, B.H. (2005) Development of Intelligent Mould Shop. Computer-Aided Design \& Appli- 
cations, 2, 619-626. http://dx.doi.org/10.1080/16864360.2005.10738326

[5] Lou, H.H. and Huang, Y. (2006) Electroplating. In: Encyclopedia of Chemical Processing, Taylor and Francis, New York, 1-10.

[6] American Society for Testing and Materials (2008) ASTM B832-93 Standard Guide for Electroforming with Nickel and Copper. ASTM International, West Conshohocken.

[7] Shyu, R.F., Yang, H. and Lee, J.H. (2008) Micro-Electroforming Metallic Bipolar Electrodes for Mini-DMFC Stacks. Proceedings DTIP of MEMS and MOEMS, 9-11 April 2008, 192-196.

[8] Bari, G.A. (2010) Electrodeposition of Nickel. In: Schlesinger, M. and Paunovic, M., Eds., Modern Electroplating, 5th Edition, John Wiley \& Sons, New York, 79-111. 